J. Clin. Chem. Clin. Biochem.

Vol. 24, 1986, pp. 877-888

(C) 1986 by Walter de Gruyter \& Co. Berlin - New York

\title{
Methodische Aspekte zur photometrischen Bestimmung der Prothrombinzeit mittels chromogener Substrate
}

\author{
Von F. Dati, H.-J. Kolde, N. Heimburger \\ Forschungslaboratorien der Behringwerke AG, Marburg und \\ F. Keller
}

Zentrallabor der Med. Universitätsklinik, Würzburg

(Eingegangen am 20. Mai/1. Oktober 1986

Zusammenfassung: Es wird eine Methode zur photometrischen Bestimmung der Prothrombinzeit (PT, Thromboplastinzeit, "Quick-Wert") mit einem chromogenen Substrat beschrieben. Das Reagenz besteht aus humanem Plazenta-Thromboplastin, einem chromogenen Substrat für Thrombin, Calcium, einem Heparinantagonisten und einem Puffer. Die neue Prothrombinzeit-Methode wurde anhand internationaler Referenzpräparationen für Thromboplastin kalibriert. Das Reagenz spricht empfindlich auf eine Verminderung der Gerinnungsfaktoren des exogenen Systems an, jedoch nicht auf Heparin im Konzentrationsbereich bis etwa $1 \mathrm{IU} / \mathrm{ml}$. Die Präzision dieser schnellen und einfachen Bestimmung ist mit üblichen mechanisierten klinisch-chemischen Verfahren vergleichbar.

\section{Methodological aspects of the photometric determination of prothrombin time using chromogenic substrates}

Summary: A method for photometric determination of prothrombin time (PT) with a chromogenic peptide as substrate is described. The reagent contains human placental thromboplastin, a chromogenic substrate, calcium, a heparin antagonist and buffer. The new prothrombin time method has been calibrated against international reference preparations for thromboplastin. The reagent is sensitive to deficiency of all coagulation factors of the extrinsic pathway. However, it is not sensitive for heparin up to $1 \mathrm{IU} / \mathrm{ml}$. The precision of this fast and simple method is comparable to that of mechanised assays for clinical chemistry.

\section{Einfilihrung}

Die Bestimmung der Prothrombinżeit (PT, Thromboplastinzeit, TPZ, Quick-Test) ist die häufigst durchgeführte Analyse im Gerinnungslabor. Sie geht auf eine von $A$. Quick berreits in den dreißiger Jahren entwikkelte Methode zurück (1). Durch verbesserte Reagenzien und auch Geräte wurde die Methode zwar verfeinert, jedoch bereitet der Vergleich der Meßwerte verschiedener Laboratorien gewisse Schwierigkeiten. Durch Einführung der Begriffe „Prozent der Norm“ oder auch „Prothrombin-Ratio“ wurde versucht, die Methode zu standardisieren, jedoch fanden sich weiterhin erhebliche Diskrepanzen beim Vergleich der Resultate von Labor zu Labor (2-4).
Auch die Benutzung der von der WHO empfohlenen Internationalen Normalisierten Ratio (INR) (die Umrechnung der Prothrombin-Ratio mit Hilfe des Internationalen Sensitivity Index, ISI) führt immer noch zu Diskrepanzen, die sich durch Verwendung unterschiedlicher Meßprinzipien zur Erfassung des Gerinnsels wohl nie ganz vermeiden lassen werden $(5-7)$.

Eine grundsätzlich andere Art von Gerinnungsanalytik erlauben die chromogenen Substrate (8). Diese wurden zunächst für die Bestimmung einzelner Gerinnungsfaktoren und deren Inhibitoren eingesetzt (9), finden heute aber auch Gebrauch in photometrischen "Globaltests“ wie Prothrombinzeit oder partielle 
Thromboplastinzeit $(10-15)$. Prinzipiell bietet die Photometrie bessere Möglichkeiten der Standardisierung, da beim Einsatz chromogener Substrate die Erkennung des Endpunktes nicht mehr von der der sehr störanfälligen Bildung von Fibrin abhängt. Auch sollte die Messung der Aktivität des exogenen Gerinnungsweges in Fällen von Dysfibrinogenämie, bei Fibronogenmangel oder auch bei Patienten während einer Fibrinolysetherapie möglich sein (9).

Im folgenden wird über die Eigenschaften eines neuen Reagenzes für die photometrische Bestimmung der Prothrombinzeit berichtet, das als Aktivator humanes Thromboplastin aus Plazenta verwendet. Das gleiche Thromboplastin wurde zuvor zur Herstellung eines standardisierten Reagenzes für die koagulometrische Bestimmung der Prothrombinzeit benutzt, das sehr ähnliche Eigenschaften aufweist wie das Referenzthromboplastin BCT (British Comparative Thromboplastin) (16).

\section{Material und Methoden}

Reagenzien für die photometrische ProthrombinzeitMethode

Die photometrische Methode zur Bestimmung der Prothrombinzeit verwendet das neu entwickelte Reagenz Chromoquick ${ }^{\circledR}$ (Behringwerke AG, Marburg) (17-19). Dieses Reagenz besteht aus humanem Plazenta-Thromboplastin, dem chromogenen Substrat für Thrombin Tosyl-glycyl- $L$-prolyl- $L$-arginyl-5-amino-2-nitrobenzoesäure-isopropylamid $\left(K_{\mathrm{m}}=17 \mu \mathrm{mol} / 1 \mathrm{mit} \mathrm{hu}-\right.$ manem $\alpha$-Thrombin) (17), Calciumionen, einem Heparinantagonisten (Polybren ${ }^{\circledR}$, Hexadimethrinbromid) und HEPESPuffer.

Reagenzien für die koagulometrischen Prothrombinzeit-Methoden

Die koagulometrischen Prothrombinzeit-Methoden wurden mit Thromboplastinen aus Human-Plazenta oder aus Human-Hirn (British Comparative Thromboplastin BCT) an einem herkömmlichen Koagulometer (Schnitger/Gros, Fa. Amelung, Lemgo) oder manuell (Häkchen-Methode) durchgeführt.

\section{Thromboplastine aus humaner Plazenta}

Thromborel ${ }^{\circledR}$ S („HPT I“) (Behringwerke AG, Marburg), Charge Nr. 130683, International Sensitivity Index (ISI): 1,14.

Calcium-Thromboplastin („HPT II“) (Behringwerke AG, Marburg), weniger Faktor VII-empfindlich.

\section{Thromboplastine aus humanem Hirn}

British Comparative Thromboplastin („BCT“) (U.K. Reference Lab. for Anticoagulant Reagents and Control, Manchester, U. K.), Charge Nr. 235 (ISI: 1,098; L. A. Poller, persönliche Mitteilung) und Charge Nr. 099 (ISI: 1,047).

\section{Andere Reagenzien}

Referenzplasma: Standard-Human-Plasma (Behringwerke AG, Marburg)

Plasmen mit verlängerten Prothrombinzeiten: Pathoplasma I und II (Behringwerke AG, Marburg)
Faktoren-Mangelplasmen: F II-, F V-, F VII-, F X-Mangelplasmen mit eincr Restaktivität $0-1 \%$ (Behringwerke AG, Marburg)

Heparin: Liquemin ${ }^{\circledR} 5000 \mathrm{IU} / \mathrm{ml}$ (Hoffmann-La Roche, Grenzach)

Calciumchlorid-Lösung $0,025 \mathrm{~mol} / \mathrm{l}$

Natriumcitrat-Lösung $0,11 \mathrm{~mol} / \mathrm{l}$.

\section{Durchführung der Prothrombinzeit'Bestimmung}

\section{Photometrische Prothrombinzeit-Methode}

Das Reagenz für die photometrische Prothrombinzeit-Bestimmung (Chromoquick) liegt als Lyophilisat vor und wurde mit dest. Wasser rekonstituiert und vor Gebrauch mindestens $15 \mathrm{~min}$ bei $+37^{\circ} \mathrm{C}$ inkubiert.

Testansatz: In eine auf $+37^{\circ} \mathrm{C}$ vorgewärmte Halbmikroküvette wurden $50 \mu \mathrm{l}$ Citratplasma pipettiert und dann $500 \mu \mathrm{l}$ Reagenz (auf $+37^{\circ} \mathrm{C}$ temperiert) zugegeben. Die Reaktion wurde in einem modifizierten mikroprozessor-gesteuerten Photometer (PM 300, Riele, Berlin) verfolgt; es wurde automatisch die Zeit ab Zugabe des Reagenzes gemessen, bis eine Zunahme der Absorbanz von 0,1 erfolgt war.

Einige Messungen erfolgten unter Zuhilfenahme eines externen Computers mit dem Zentrifugalanalysator Cobas Bio (Fa. Hoffman-La Roche, Grenzach), der mit einem speziellen Thermoblock ausgerüstet wurde.

\section{Koagulometrische Prothrombinzeit-Methoden}

Human-Plazenta-Thromboplastine (HPT I und HPT II):

Die Thromboplastin-Reagenzien wurden mit dest. Wasser gelöst und vor Gebrauch mindestens 15 min bei $+37^{\circ} \mathrm{C}$ inkubiert.

Testansatz: In auf $+37^{\circ} \mathrm{C}$ vorgewärmte Glas- oder Kunststoffröhrchen wurden $0,1 \mathrm{ml}$ Plasma pipettiert, $1 \mathrm{~min}$ bei $+37^{\circ} \mathrm{C}$ inkubiert und dann $0,2 \mathrm{ml}$ Reagenz (auf $+37^{\circ} \mathrm{C}$ temperiert) zugegeben.

Mit der Zugabe des Reagenzes wurde die Meßstelle am Koagulometer bzw. die Stoppuhr gestartet und die Gerinnungszeit bestimmt.

British Comparative Thromboplastin (BCT):

Die Abfüllung dieses Thromboplastins wurde in $1 \mathrm{ml}$ Rekonstitutionslösung gelöst und $5 \mathrm{~min}$ bei Raumtemperatur stehen gelassen (21).

Testansatz: In auf $+37^{\circ} \mathrm{C}$ vorgewärmte Glas- oder Kunststoffröhrchen wurden $0,1 \mathrm{ml}$ BCT-Reagenz und $0,1 \mathrm{ml}$ Plasma pipettiert und $1 \mathrm{~min}$ bei $+37^{\circ} \mathrm{C}$ inkubiert, danach $0,1 \mathrm{ml}$ Calciumchlorid-Lösung $0,025 \mathrm{~mol} / 1$ (auf $+37^{\circ} \mathrm{C}$ temperiert) zugegeben.

Mit Zugabe der Calciumchlorid-Lösung wurde die Meßstelle am Koagulometer bzw. die Stoppuhr gestartet und die Gerinnungszeit bestimmt.

Sämtliche Bestimmungen der Prothrombinzeit wurden immer in Duplikat durchgeführt. Es wurde jeweils dër Mittelwert der Doppelbestimmung für die weitere Berechnung verwendet. Im Falle von größeren Abweichungen bei der Doppelbestimmung wurde die Bestimmung wiederholt.

\section{Erstellen der Bezugskurven}

Die Erstellung der Bezugskurven für die Prothrombinzeit-Bestimmung mit den verschiedenen Thromboplástinen erfolgte mit einem Frischplasma-Pool (mindestens 50 männliche Spender) bzw. mit einem Standard-Human-Plasma entweder unverdünnt oder durch Verdünnen mit isotoner Natriumchloridlösung in Vẹrhälttis $1: 2,1: 4,1: 8,1: 16$. 


\section{Darstellung der Ergebnisse}

Die Darstellung der Ergebnisse erfolgt in Sekunden (s), in „Prozent-der-Norm“ (\%) oder als Prothrombin-Ratio (PR).

\section{Prozent-Werte}

Die gemessenen Gerinnungszeiten wurden anhand einer individuellen Referenzkurve in Prozent-Werte (Prozent der Prothrombinzeit eines Referenzplasmas $=100$ Prozent der Norm) umgerechnet. Um diese Referenzkurven für die Prothrombinzeit erstellen zu können, werden die Gerinnungszeiten des Referenzplasmas bzw. dessen Verdünnungen den Werten der jeweiligen prozentualen Verdünnung au؟ logarithmischer Skala zugeordnet.

Die optimale Kurve, die eine realitätsnahe Anpassung der Meßwerte untereinander gewährleistet, wird mit Hilfe von Tischrechnern unter Verwendung der Methode der polygonalen Interpolation (22) errechnet.

\section{Prothrombin-Ratio (PR)}

Die Prothrombin-Ratios (oder Quotienten-Werte) werden aus den Quotienten der Gerinnungszeiten der untersuchten Plasmen und der Gerinnungszeit eines vor der Versuchsreihe eingesetzten Referenzplasmas errechnet. Dieser Quotient ist im Falle, daß das Patientenplasma die gleiche Gerinnungszeit wie das Referenzplasma zeigt, 1,0 und im Falle einer auf das Doppelte verlängerten Gerinnungszeit 2,0.

Die Prothrombin-Ratio-Werte erlauben, die Prothrombinzeit eines oral antikoagulierten Patienten unter Berücksichtigung des für die betreffende Thromboplastincharge spezifischen "Empfindlichkeitsfaktors“" ("International Sensitivity Index" = "ISI") aus der Gleichung INR $=\mathrm{PR}^{\mathrm{ISI}}$ in international gültige "normalisierte" Prothrombin-Ratio („International Normalized Ratio“ = „INR“) umżurechnen.

Bestimmung der Faktorenempfindlichkeit (F II, FV, F VII, F X)

Die Einstellung unterschiedlicher Faktorenkonzentrationen (100, 50, 25, 5, $1 \%$ der Konzentration eines Referenzplasmas) erfolgte durch Mischmengen von tiefgefroren aufbewahrtem Plasmapool mit normaler Prothrombinzeit mit dem jeweiligen Faktoren-Mangelplasma in folgenden Verhältnissen: $1 \mathrm{ml} / 0$; $0,5 \mathrm{ml} / 0,5 \mathrm{ml} ; 0,25 \mathrm{ml} / 0,75 \mathrm{ml} ; 0,5 \mathrm{ml} / 0,95 \mathrm{ml} ; 0,01 \mathrm{ml} / 0,99 \mathrm{ml}$.

\section{Bestimmung der Heparinempfindlichkeit}

Die Testung der Heparinempfindlichkeit erfolgte durch Bestimmung der Prothrombinzeit in verschiedenen Abfüllungen von Standard-Human-Plasma, das mit steigenden Heparin-Konzentrationen von 0,1 bis $1,0 \mathrm{IU} / \mathrm{ml}$ in isotoner NatriumchloridLösung aufgẹösöt wụrde.

\section{Überprüfung von möglichen Interferenzen}

Der Einfluß von erhöhten Triglyceriden wurde nach Zusatz von Chylomikronen, die durch Dichtegradientenzentrifugation aus lipämischen Seren gewonnen wurden, untersucht. Zur Überprüfung des Hämoglobineinflusses wurden humane Erythrocyten durch Zusatz von Wasser lysiert und dem Plasma zugesetzt. Als Basissubstanz zur Untersuchung einer möglichen Störung der Reaktion durch ikterische Plasmen wurde ein Bilirubin-
Standard verwendet. Weiterhin wurden verschiedene Plasmen von Patienten mit Lebererkrankungen, die erhöhte Bilirubinkonzentrationen ( $>52 \mu \mathrm{mol} / \mathrm{l}$ ) aufwiesen, für die Vergleichsuntersuchungen verwendet.

\section{Statistische Auswertungen}

Für dẹn Vergleich der photometrischen Prothrombinzeit-Methode mit den koagulometrischen Prothrombinzeit-Tests wurde das nicht-parametrische Verfahren nach Passing \& Bablok herangezogen $(23,24)$.

\section{Kontrollproben und Patienten}

Im Rahmen der hier durchgeführten Untersuchungen wurden lyophilisierte Kontroll- und Standard-Human-Plasmen, z. B. zur Überprüfung der Präzision, der Faktorenempfindlichkeit und des Heparineinflusses, benutzt. Zum Methodenvergleich wurden sowohl Plasmen von Patienten mit Lebererkrankungen und unter oraler Antikoagulantien-Therapie als auch von gesunden Probanden verwendet.

\section{Ergebnisse \\ Meßprinzip}

In Abbildung 1 wird der Reaktionsablauf des photometrischen Prothrombinzeit-Tests für ein Plasma mit normaler Prothrombinzeit $(\mathrm{N})$ und ein Plasma mit verlängerter Prothrombinzeit und mit erniedrigtem Fibrinogengehalt $(\mathrm{P})$ gezeigt. Nach Vermischen von Plasma und Reagenz wird durch Thromboplastin Faktor VII aktiviert, der Faktor X zu Faktor Xa aktiviert. Faktor Xa setzt dann unter Mitwirkung von Faktor Va, Phospholipiden und Calciumionen aus Prothrombin das Enzym Thrombin frei, das das chromogene Substrat Tos-Gly-Pro-Arg-ANBA-IPA spaltet und das gelbgefärbte 5-Amino-2-nitrobenzoe-

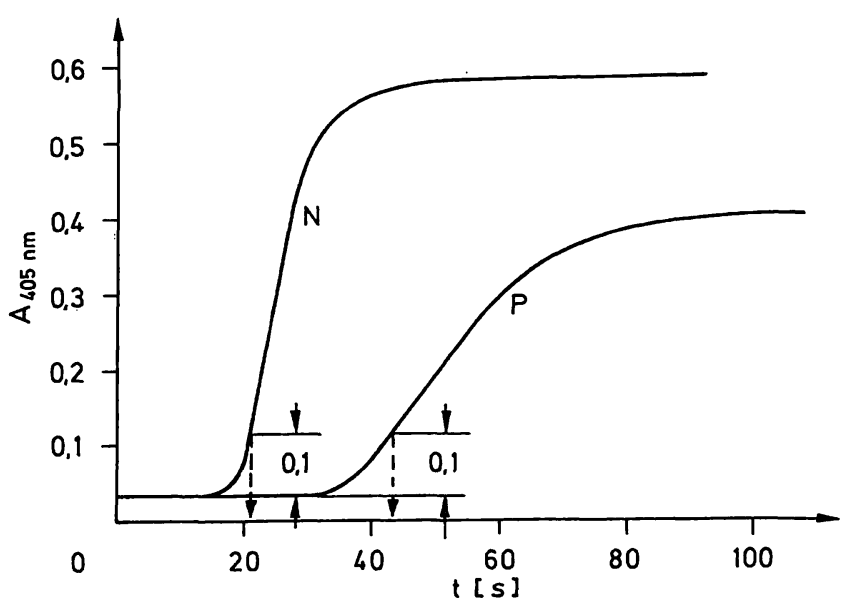

Abb. 1. Reaktionskurven des photometrischen Prothrombinzeit-Tests für ein Plasma mit normaler Prothrombinzei (N) und für ein Plasma mit verlängerter Prothrombinzeit und mit erniedrigtem Fibrinogengehalt $(P)$. 
säure-isopropylamid (Abb. 2) freisetzt. Nach einer lag-Phase erzeugt die Bildung von Thrombin einen starken Anstieg der zuvor konstanten Absorbanz, die bei $405 \mathrm{~nm}$ gemessen wird. Meßgrößc ist dic Zeit, die nach Zusammenführen von Probe und Reagenz bis zum Erreichen einer Absorbanzzunahme von 0,1 gemessen wird. Die Zeitmessung erfolgt automatisch durch den Mikroprozessor des modifizierten Photometers. Mittlerweile steht eine weiterentwickelte Form dieses Photometers zur simultanen Analyse von vier Proben zur Verfügung (Chromotimer ${ }^{\circledR}$, Behringwerke AG) (25). Nach Hydrolyse des in begrenzter Menge $(50 \mu \mathrm{mol} / \mathrm{l})$ vorliegenden Substrates erfolgt die Bildung eines Fibringerinnsels, da das jetzt in relativ großer Menge vorliegende Thrombin auch Fibrinogen, sein natürliches Substrat, spalten kann. Diese Reaktion ist zu Beginn der Thrombinbildung durch das chromogene Substrat, das gegenüber Fibrinogen in einem ca. 60 fachen molaren Überschuß bei ähnlichem $K_{\mathrm{m}}$-Wert (20) vorliegt, gehemmt.

Im Unterschied zu konventionellen ProthrombinzeitTests ist die chromogene Prothrombinzeit-Methode unabhängig vom Gehalt an Fibrinogen und Fibrinogen-Spaltprodukten. Andererseits läßt sich der Fibrinogengehalt aus der am Ende der Reaktion vorliegenden Absorbanzdifferenz abschätzen.
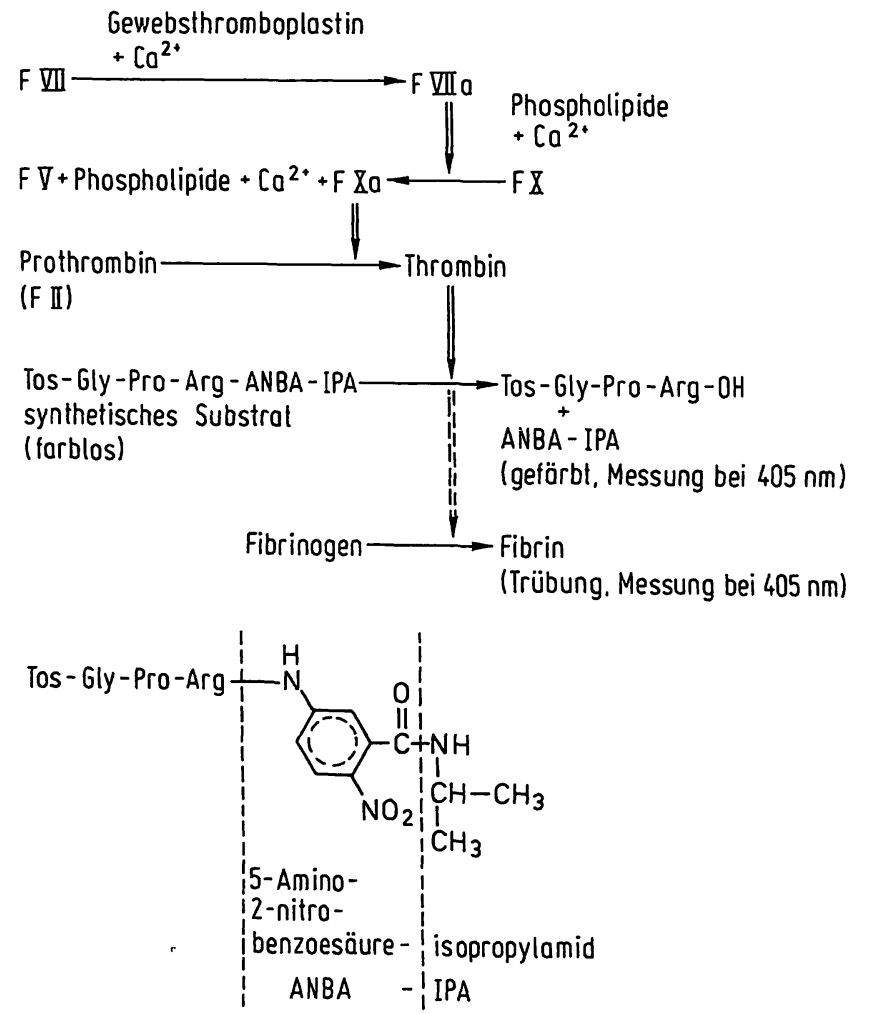

Abb. 2. Schematische Darstellung des Testprinzips der photometrischen Prothrombinzeit-Methode.

\section{Bezugskurve}

Abbildung 3 zeigt eine Bezugskurve, die durch Verdünnen von einem Referenzplasma mit normaler Prothrombinzeit mit physiologischer Natriumchloridlösung erhalten wurde. Der $100 \%$-Wert liegt bei etwa $20 \mathrm{~s}$ und damit höher als bei den üblichen koagulometrischen Prothrombinzeit-Tests, in denen Plasma im Verhältnis $1+2$ verdünnt wird. Bei der photometrischen Prothrombinzeit-Methode beträgt dagegen das Verdünnungsverhältnis $1+10$. Die Reaktionszeit eines Normalplasmas mit dem neuen chromogenen Prothrombinzeit-Reagenz liegt also etwa im Bereich der sogenannten II-, VII-, X-Reagenzien, ist aber um etwa $10 \mathrm{~s}$ kürzer als die beschriebene Reaktionszeit eines photometrischen Prothrombinzeit-Reagenzes auf Basis von Kaninchenhirn-Thromboplastin (1012).

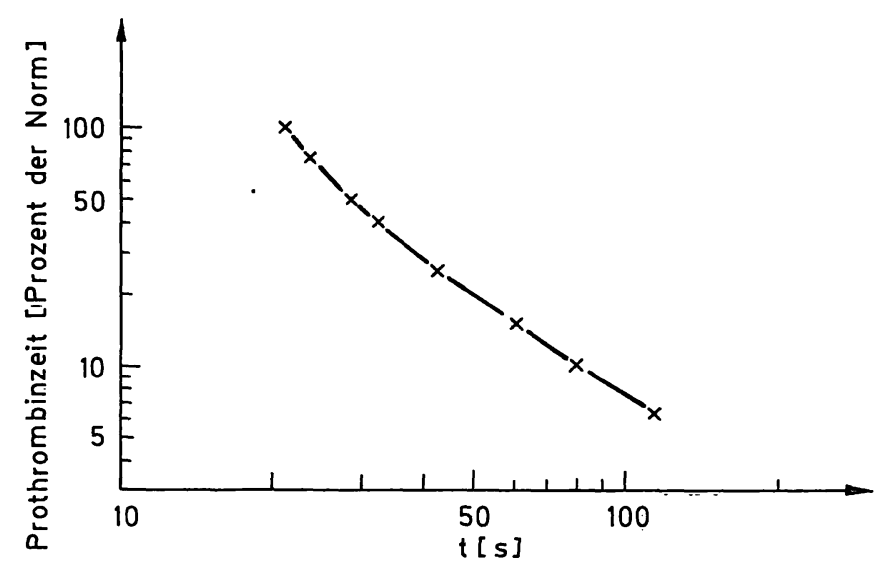

Abb. 3. Prothrombinzeit-Bezugskurve (Prozent der Norm) für die photometrische Methode. Die Werte sind im doppelt-logarithmischen System aufgetragen. Methode: Polygonale Interpolation.

\section{Präzision}

Die Reproduzierbarkeit wurde unter Verwendung unterschiedlicher Reagenzchargen sowohl an lyophilisierten Kontrollplasmen mit normalen und verlängerten Prothrombinzeiten als auch in verschiedenen $\mathrm{Pa}$ tientenseren untersucht (26).

Für die Präzision in der Serie (Intra-assay-Varianz) bei einer 20 fachen Bestimmung (Tab. 1) wurden Variationskoeffizienten von 0,6 bis $2,0 \%$ bei der Berechnung auf der Basis von Sekunden und von 1,1 bis $3,0 \%$ bei der Berechnung in Prozent der Norm erhalten. Die Präzision von Tag zu Tag (Inter-assay-Varianz) ergab für die Prothrombinzeit bei drei Bestimmungen an fünf verschiedenen Tagen (Tab. 2) Variationskoeffizienten von 1,4 bis $3,4 \%$ bei der Berechnung auf Sekundenbasis und von 2,2 bis $5 ; 8 \%$ bei der Bereçhnung in Prozent der Norm. 
Tab. 1. Präzision in der Serie für die photometrische Prothrombinzeit-Methode (20 Bestimmungen).

\begin{tabular}{|c|c|c|c|c|c|c|}
\hline \multirow{2}{*}{$\begin{array}{l}\text { Probe } \\
\text { Nr. }\end{array}$} & \multicolumn{3}{|c|}{ Sekundenwerte } & \multicolumn{3}{|c|}{ Prozent der Norm } \\
\hline & $\begin{array}{l}\text { Mittelwert } \\
(\bar{x})\end{array}$ & $\begin{array}{l}\text { Standard- } \\
\text { abweichung } \\
( \pm s)\end{array}$ & $\begin{array}{l}\text { Variations- } \\
\text { koeffizient } \\
(\%)\end{array}$ & $\begin{array}{l}\text { Mittelwert } \\
(\overline{\mathbf{x}})\end{array}$ & $\begin{array}{l}\text { Standard- } \\
\text { abweichung } \\
( \pm s)\end{array}$ & $\begin{array}{l}\text { Variations- } \\
\text { koeffizient } \\
(\%)\end{array}$ \\
\hline 1 & 21,6 & 0,15 & 0,7 & 78,0 & 1,20 & 1,5 \\
\hline 2 & 24,0 & 0,18 & 0,7 & 61,7 & 1,10 & 1,8 \\
\hline 3 & 51,2 & 0,37 & 0,7 & 16,6 & 0,18 & 1,1 \\
\hline 4 & 77,5 & 1,52 & 2,0 & 9,4 & 0,25 & 2,6 \\
\hline 5 & 31,6 & 0,30 & 1,0 & 35,7 & 0,64 & 1,8 \\
\hline 6 & 39,2 & 0,31 & 0,8 & 24,7 & 0,31 & 1,3 \\
\hline 7 & 61,9 & 0,66 & 1,1 & 12,6 & 0,20 & 1,6 \\
\hline 8 & 33,3 & 0,22 & 0,7 & 32,5 & 0,38 & 1,2 \\
\hline 9 & 20,0 & 0,27 & 1,3 & 93,6 & 2,78 & 3,0 \\
\hline 10 & 22,0 & 0,13 & 0,6 & 75,4 & 1,08 & 1,4 \\
\hline
\end{tabular}

Tab. 2. Präzision von Tag zu Tag für die photometrische Prothrombinzeit-Methode (3 Bestimmungen an 5 verschiedenen Tagen).

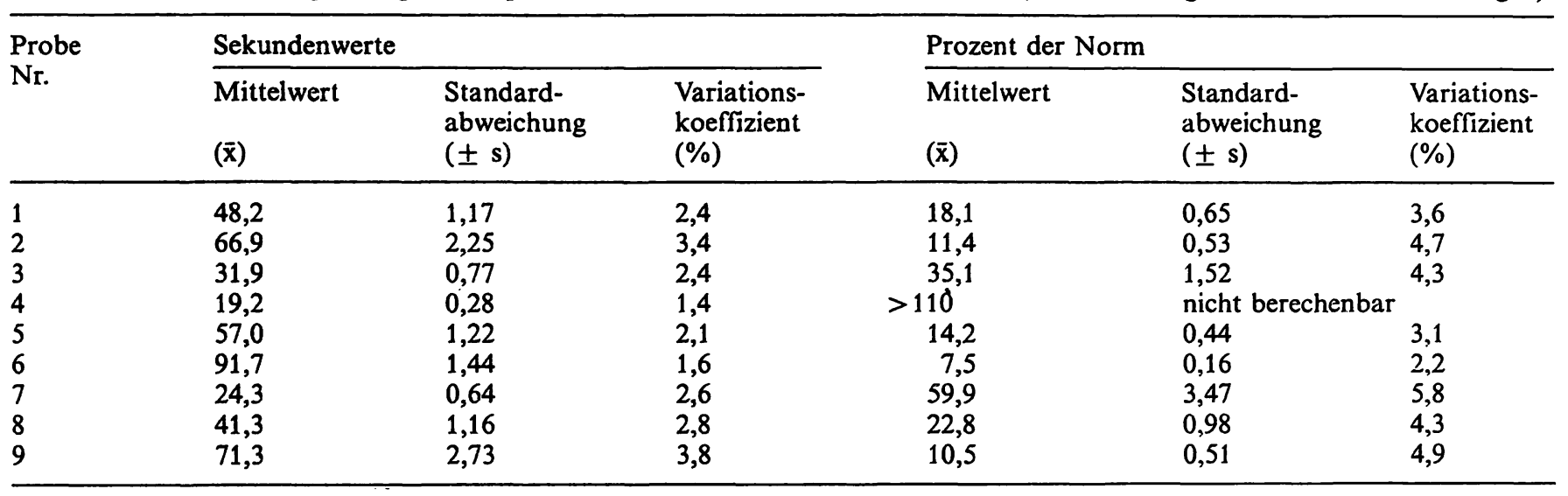

Bei der Dúrchführung der photometrischen Prothrombinzeit-Bestimmung an einem Zentrifugalanalysator ergaben sich für die Ergebnisse in Sekundenwerten Variationskoeffizienten in der Serie $(n=20)$ von $1,6 \%(\overline{\mathrm{x}}=19,5 \mathrm{~s}), 0,97 \%(\overline{\mathrm{x}}=35,6 \mathrm{~s})$ und $1,0 \%$ $(\overline{\mathrm{x}}=65,0 \mathrm{~s})(J$. Flückiger \& E. Hänseler; persönliche Mitteilung).

\section{Einfluß von Mangel verschiedener Gerin- nungsfaktoren}

Der Einfluß der Verminderung einzelner Gerinnungsfaktoren auf die photometrische Methode wurde invitro untersucht, indem ein Referenzplasma mit verschiedenen Mangelplasmen verdünnt wurde und damit der Gehalt der entsprechenden Faktoren vermindert wurde. Abbildung 4 zeigt, daß bereits relativ geringe Verminderungen der für die Prothrombinzeit relevanten vier Gerinnungsfaktoren II, V, VII und X zu verlängerten Reaktionszeiten führen. Das Reagenz für die photometrische Prothrombinzeit-Bestimmung ähnelt in dieser Hinsicht dem Reagenz für die koagulometrische Methode, was ebenfalls humanes Thromboplastin aus Plazenta enthält und eine hohe Faktorenempfindlichkeit zeigt (16).

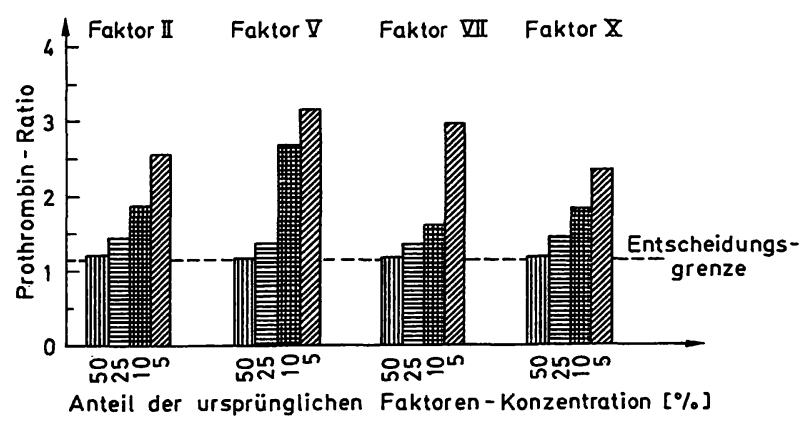

Abb. 4. Faktorenempfindlichkeit des photometrischen Prothrombinzeit-Tests. Aufgetragen ist die Zeitverlängerung (Prothrombin-Ratio) durch die jeweilige Faktorenverminderung $(50,25,10,5 \%$ der Norm) gegenüber einem Referenzplasma (Konzentration dieses Plasmas: $100 \%$ der Norm).

Bei Patienten mit erworbenen Faktorenmängeln im exogenen Gerinnungssystem zeigen daher auch beide Reagenzien diese Gerinnungsstörungen ähnlich empfindlich an (A. Girolami; persönliche Mitteilung).

\section{Heparineinflu $\beta$}

Zur Ermittlung des Heparineinflusses wurde die Prothrombinzeit-Bestimmung in verschiedenen Abfül- 
lungen eines Kontrollplasmas mit normaler Prothrombinzeit, das unterschiedliche Heparinkonzentrationen zwischen 0,1 und $1,0 \mathrm{IU} / \mathrm{ml}$ enthielt, bestimmt (Abb. 5). Aus den Ergebnissen konnte festgestellt werden, daß das geprüfte chromogene Prothrombinzeit-Reagenz, auch bedingt durch den dem Reagenz zugesetzten Heparinantagonisten, einen Neutralisationseffekt für Heparin bis zu etwa 1,0$1,25 \mathrm{IU} / \mathrm{ml}$ Plasma aufweist.

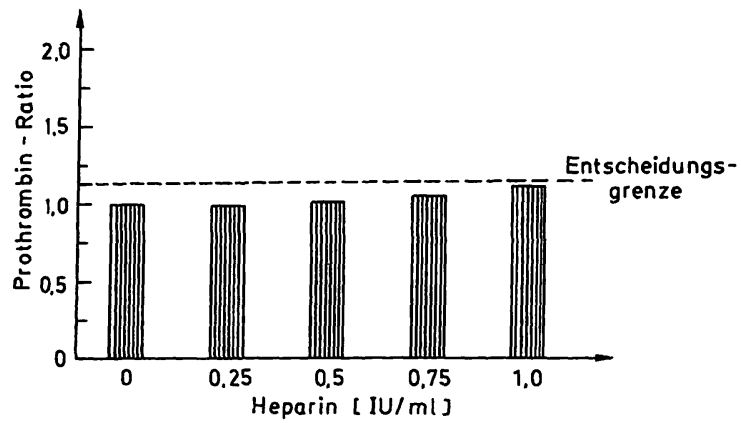

Abb. 5. Einfluß von Heparin in steigenden Konzentrationen auf die photometrische Prothrombinzeit-Bestimmung.

\section{Einfluß möglicher Interferenzen}

Der Einfluß von erhöhten Tryglycerid-, Bilirubin- und Hämoglobinkonzentrationen wurde, wie unter ,Methoden' beschrieben, untersucht.

Nach dem Zusatz der mit Ultrazentrifugation isolierten Chylomikronen zu Plasmen im Verhältnis von 1:30 bzw. 1:10 zeigten die für diese Versuche verwendeten Plasmen einen hohen Trübungsgrad $\left(\mathrm{A}_{40 \mathrm{snm}}>\right.$ 2,0). Diese erhöhte Trübung verursachte keinen Unterschied in den Prothrombinzeit-Werten, die in den Plasmen mittels photometrischer ProthrombinzeitMethode gemessen werden (Tab. 3).

Mögliche Interferenzen durch Hämolyse wurden durch Zugabe von Hämoglobin (aus lysierten Erythrocyten) bis zu einer Konzentration von $20 \mathrm{~g} / \mathrm{l}$ simuliert. Unter diesen Bedingungen konnte keine Störung beobachtet werden (Tab. 4). Es zeigten sich keine Unterschiede in den Prothrombin-Ratios der mit koagulometrischen und photometrischen Prothrombinzeit-Tests untersuchten Plasmen durch $\mathrm{Zu}$ satz von Hämoglobin bis zu Konzentrationen zwischen 5 und $10 \mathrm{~g} / \mathrm{l}$. Erst bei physiologisch in Plasma praktisch nie erreichbaren Hämoglobinkonzentrationen von $10 \mathrm{~g} / 1$ wurde die Prothrombinzeit-Bestimmung gestört.

Verschiedene Plasmen mit hohen Bilirubinkonzentrationen wurden mit der photometrischen und der koagulometrischen Prothrombinzeit-Methode untersucht (Tab. 5). Es konnten keine bedeutsamen Differenzen
Tab. 3. Einfluß der Lipämie auf die photometrische Prothrombinzeit-Methode (Werte in Sekunden). Vergleich der Prothrombin-Ratio-Werte in klaren und in trüben Plasmen.

\begin{tabular}{llll}
\hline \multirow{2}{*}{$\begin{array}{l}\text { Plasma } \\
\text { Nr. }\end{array}$} & \multicolumn{3}{l}{ Photometrischer Prothrombinzeit-Test (s) } \\
\cline { 2 - 4 } & Keine Trübung & Lipide 1:30 & Lipide 1:10 \\
\hline 1 & 59,8 & 57,3 & .1 \\
2 & 29,5 & 29,0 & 57,6 \\
3 & 31,3 & 30,8 & 30,8 \\
4 & 40,6 & 39,1 & 35,2 \\
5 & 40,3 & 39,6 & 40,0 \\
6 & 41,5 & 40,2 & 40,0 \\
\hline
\end{tabular}

Tab. 4. Einfluß der Hämolyse auf die photometrische Prothrombinzeit-Methode (Werte in Prothrombin-Ratio). Vergleich mit einem koagulometrischen Prothrombinzeit-Test (HPT I).

\begin{tabular}{|c|c|c|c|c|}
\hline \multirow[t]{2}{*}{$\begin{array}{l}\text { Plasma } \\
\text { Nr. }\end{array}$} & \multirow{2}{*}{$\begin{array}{l}\text { Hämo- } \\
\text { globin- } \\
\text { konzen- } \\
\text { tration } \\
(\mathrm{g} / \mathrm{l})\end{array}$} & \multirow{2}{*}{$\begin{array}{l}\text { Koagulom. } \\
\text { Prothrom- } \\
\text { binzeit-Test } \\
\text { (Prothrom- } \\
\text { bin-Ratio) }\end{array}$} & \multicolumn{2}{|c|}{$\begin{array}{l}\text { Photometrische } \\
\text { Prothrombinzèit- } \\
\text { Mẹthode }\end{array}$} \\
\hline & & & (s) & $\begin{array}{l}\text { (Pro- } \\
\text { throm- } \\
\text { bin- } \\
\text { Ratio) }\end{array}$ \\
\hline 1 & 0 & 1,66 & 32,4 & 1,54 \\
\hline 1 & 2,5 & 1,66 & 32,4 & 1,54 \\
\hline 1 & 5,0 & 1,66 & 32,3 & 1,53 \\
\hline 1 & 10,0 & 1,66 & 35,6 & 1,69 \\
\hline 1 & 20,0 & 1,66 & \multicolumn{2}{|c|}{ nicht meßbar } \\
\hline 2 & 0 & 1,61 & 33,4 & 1,58 \\
\hline 2 & 2,5 & 1,61 & 33,4 & 1,58 \\
\hline 2 & 5,0 & 1,61 & 34,4 & 1,63 \\
\hline 2 & 10,0 & 1,61 & \multirow{2}{*}{\multicolumn{2}{|c|}{$\begin{array}{l}\text { nicht meßbar } \\
\text { nicht meßbar }\end{array}$}} \\
\hline 2 & 20,0 & 1,61 & & \\
\hline 3 & $0^{\cdot \cdot}$ & 2,26 & 50,7 & 2,40 \\
\hline 3 & 2,5 & 2,26 & 50,1 & 2,37 \\
\hline 3 & 5,0 & 2,26 & 49,1 & 2,33 \\
\hline 3 & 10,0 & 2,26 & 83,2 & 3,94 \\
\hline 3 & 20,0 & 2,26 & \multicolumn{2}{|c|}{ nicht meßbar } \\
\hline
\end{tabular}

in den Prothrombin-Ratio-Werten der zwei unterschiedlichen Methoden zur Prothrombinzeit-Bestimmung festgestellt werden. Es ergab sich kein Anhalt, $\mathrm{da} B$ erhöhtes Bilirubin bis mindèstens $300 \mu \mathrm{mol} / 1$ im photometrischen Prothrombinzeit-Test wesentlich stört. Auch ein Zusatz von reinem Bilirubin zu Normalplasma störte die photometrische Prothrombinzeit-Bestimmung nicht.

\section{Ermittlung der Referenzbereiche}

Mit zwei Chargen vom chromogenen Prōthrombinzeit-Reagenz wurden zwei Kollektive vón insgessamt 217 gesunden männlichen Probanden im Alter zwischen 18 und 35 Jahren üntersucht. Es wurden Prothrombinzeit-Werte $(2,5 .-97,5$. Perz̄entil) zwischen 
Tab. 5. Einfluß von erhöhten Bilirubin-Konzentrationen auf die photometrische Prothrombinzeit-Bestimmung (Werte in Prothrombin-Ratio). Vergleich mit einem koagulometrischen Prothrombinzeit-Test (HPT I).

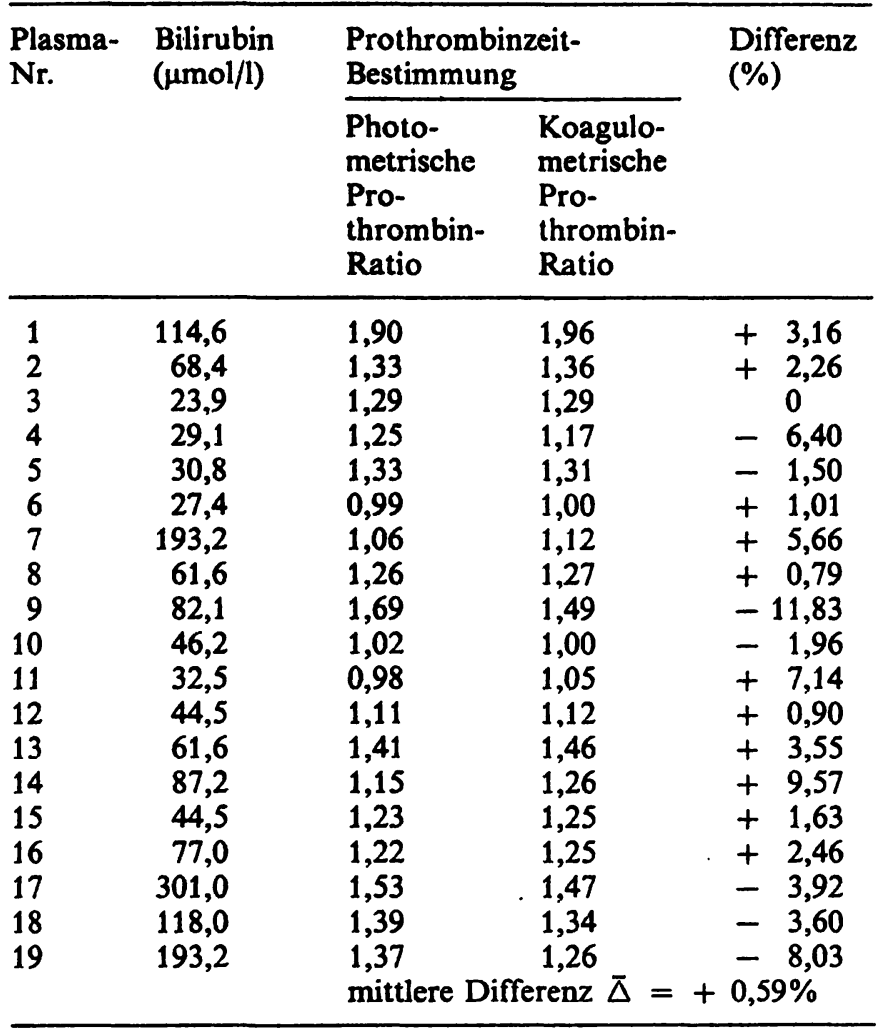

18,1 und 23,1 Sekunden bzw. 78 bis 140 Prozent der Norm bzw. 0,87 bis 1,11 Prothrombin-Ratio gemessen.

Diese Werte zeigen eine für Gerinnungstests typische Verteilung (Abb. 6), der Medianwert liegt bei 20,3 s. Als „Normalwerte“ für die Prothrombinzeit-Bestimmung mittels photometrischer Methode können Prothrombinzeit-Werte $>24 \mathrm{~s}$ bzw. $>75$ „Prozent der Norm“ bzw. <1,15 Prothrombin-Ratio betrachtet werden.

\section{Einfluß der Fibrinbildung und Fibrin(ogen)olyse}

Die photometrische Prothrombinzeit ist wesentlich weniger abhängig von der Fibrinbildung und Fibri$\mathrm{n}$ (ogen)olyse als die koagulometrische Methode und wird weder von erhöhten noch von erniedrigten Fibrinogenkonzentrationen beeinflußt. Allerdings kann der Fibrinogengehalt der Probe aus der gesamten Endabsorbanz nach Beendigung der Reaktion abgeschätzt werden. Das Vorhạndensein von Fibrin(ogen)-Spaltprodukten (FSP) beeinflußt das Ergebnis der Prothrombinzeit-Bestimmung mittels chromogener Methode nicht. Aus Abbildung 7 kann entnommen werden, daß der Abfall der Fibrinogenkonzentration und die Zunahme der Fibrin(ogen)-Spaltpro-

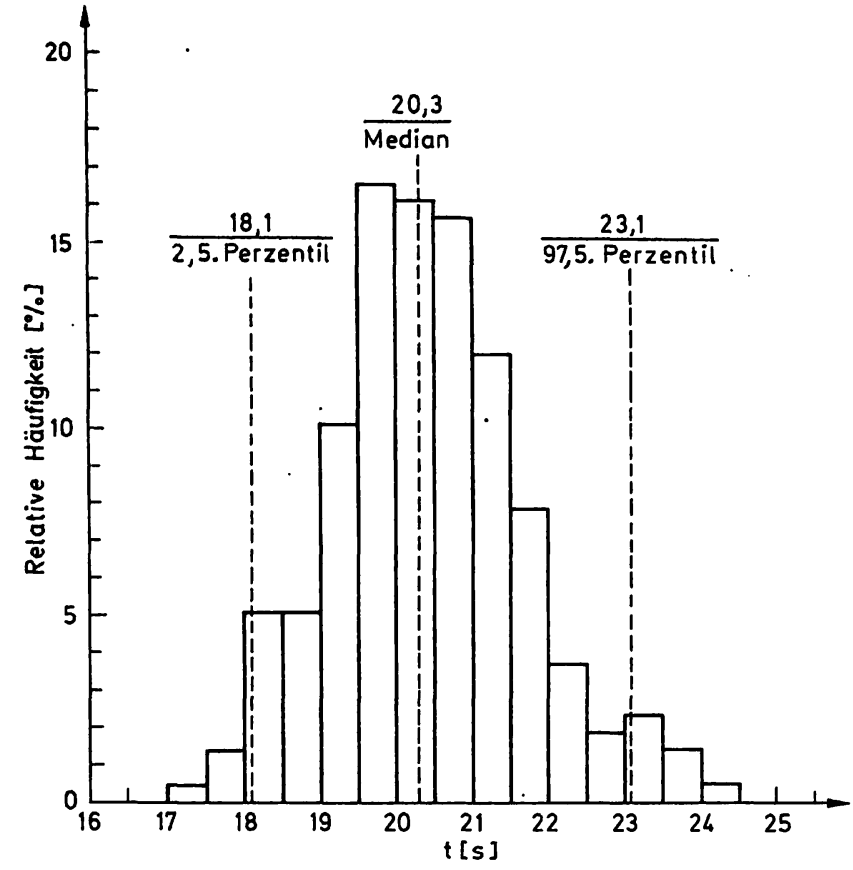

Abb. 6. Referenzwerte: Häufigkeitsverteilung der Sekundenwerte für die Prothrombinzeit-Bestimmung mit chromogenem Substrat in einem Kollektiv von 217 gesunden Probanden.

dukte (was durch die Verlängerung der Batroxobinund Thrombinzeiten angezeigt wird) im Vergleich zum koagulometrischen Prothrombinzeit-Test einen geringeren Einfluß auf die photometrische Prothrombinzeit-Bestimmung haben.

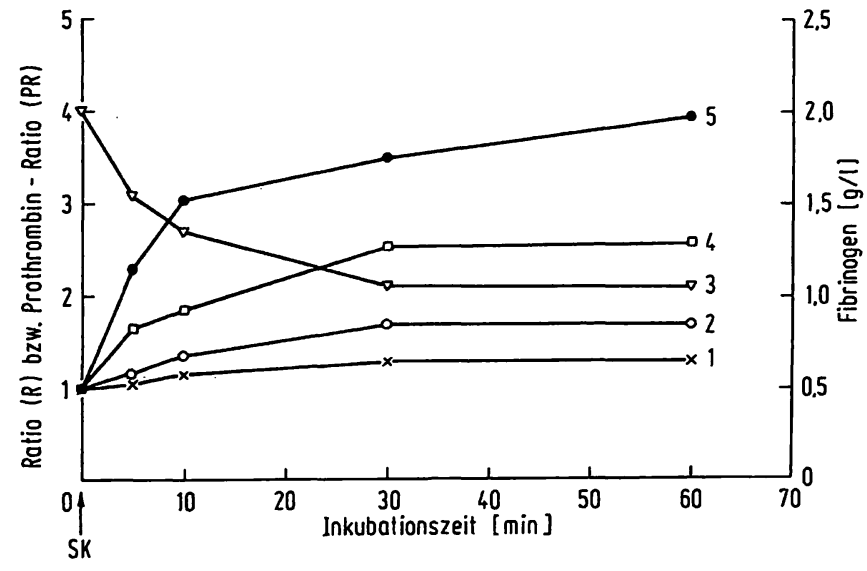

Abb. 7. Einfluß der Fibrinbildung und Fibrin(ogen)olyse auf die Prothrombinzeit-Bestimmung mittels photometrischer und koagulometrischer Methode und auf weitere Gerinnungskenngrößen. Ein Plasma mit normaler Prothrombinzeit wurde mit Streptokinase (SK) behandelt und die Reaktion nach 5, 10, 30 bzw. 60 min durch Zugabe von Aprotinin gestoppt. Durch Streptokinase wurden Fibrinogen abgebaut und gleichzeitig entstanden Fibrin(ogen)-Spaltprodukte.

1 = Koagulometrische Prothrombinzeit-Methode (Werte als Prothrombin-Ratio)

2 = Photometrische Prothrombinzeit-Methode (Werte als Prothrombin-Ratio)

3 = Fibrinogenkonzentration $(\mathrm{g} / \mathrm{l})$

$4=$ Thrombinzeit (Werte als Ratio bezogen auf ein Referenzplasma) 5 = Batroxobinzeit („Reptilasezeit“) (Werte als Ratio bezogen auf ein Referenzplasma) 
Standardisierung des chromogenen Prothrombinzeit-Reagenzes

Gemäß einer Empfehlung der WHO $(27,28)$ für koagulometrische Reagenzien wurde die für die Erprobung hergestellte Charge des chromogenen Prothrombinzeit-Reagenzes anhand verschiedener Verdünnungen von zwei Plasmapools von Gesunden und von antikoagulierten Patienten an einem internen Thromboplastin-Standard für die konventionelle Prothrombinzeit-Bestimmung kalibriert. Der Hausstandard wurde gegen ein internationales Referenzthromboplastin (British Comparative Thromboplastin Charge Nr. 235; ISI-Wert: 1,098) vorkalibriert. Für jede Charge des neuen Prothrombinzeit-Reagenzes wird nach Auftragung der Prothrombinzeiten des hier untersuchten und des Referenzreagenzes auf doppelt-logarithmischer Skala die Steigung der Regressionsgeraden nach der Methode der orthogonalen Regression berechnet (29).

Diese Steigung wird als internationaler Empfindlichkeitsfaktor (ISI = International Sensitivity Index) bezeichnet. Je mehr sich der „International Sensitivity Index" eines Reagenzes für die Prothrombinzeit-Bestimmung dem des WHO-Standards annähert, desto empfindlicher zeigt sich dieses Reagenz bei der Überwachung der oralen Antikoagulantien-Therapie. Der „International Sensitivity Index“ erlaubt über die Prothrombin-Ratio-Werte der antikoagulierten $\mathrm{Pa}$ tienten die reagenzienunabhängige und allgemein vergleichbare "International Normalized Ratio“ (INR) zu berechnen (30).

Die intern unter Verwendung von British Comparative Thromboplastin (BCT Charge Nr. 099) durchgeführte Standardisierung, die auf den Ergebnissen von 29 Plasmaproben (Proben von 12 Gesunden und 17 Antikoagulierten) basiert, ergab bei Anwendung der Methode der orthogonalen Regression die Regressionsgerade $\log \mathrm{y}=0,98 \log \mathrm{x}-0,11$ (Abb. 8). Aus deren Steigung $(0,98)$ erhält man den Faktor, der mit dem bekannten ISI-Wert der Charge des Referenzthromboplastins BCT (Charge Nr. 099; ISI-Wert: 1,047) multipliziert werden muß, um den ISI-Wert der hier untersuchten Charge des chromogenen Prothrombinzeit-Reagenzes zu ermitteln. Dieser betrug 1,03 .

Diese vorläufige interne Standardisierung wurde im Rahmen einer Evaluierung an Plasmen von $103 \mathrm{Ge}-$ sunden und von 74 Patienten unter oraler Antikoagulation überprüft. Das Ergebnis der Berechnung des "International Sensitivity Index" bestätigte mit einem Wert von 1,09 den ISI-Wert für die untersuchte Charge des chromogenen Prothrombinzeit-Reagenzes (Abb. 9).

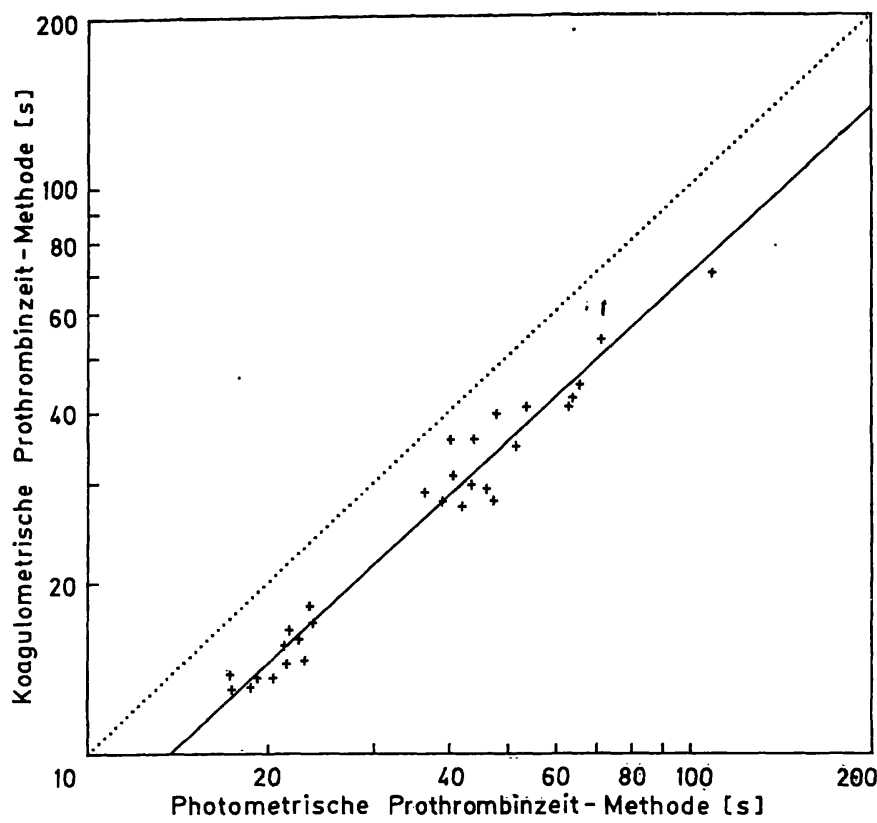

Abb. 8. Ermittlung des „International Sensitivity Index (ISI)“ für das chromogene Prothrombinzeit-Reagenz Charge 080284 (x) gegen die Referenzpräparation British Comparative Thromboplastin (BTC) Charge 099 (y). Methode: Orthogonale Regression (29). (doppelt-logarithmische Skala):

$\log (y)=0,98 \log (x)-0,11 ; n=29 ;$ ISI: 1,03

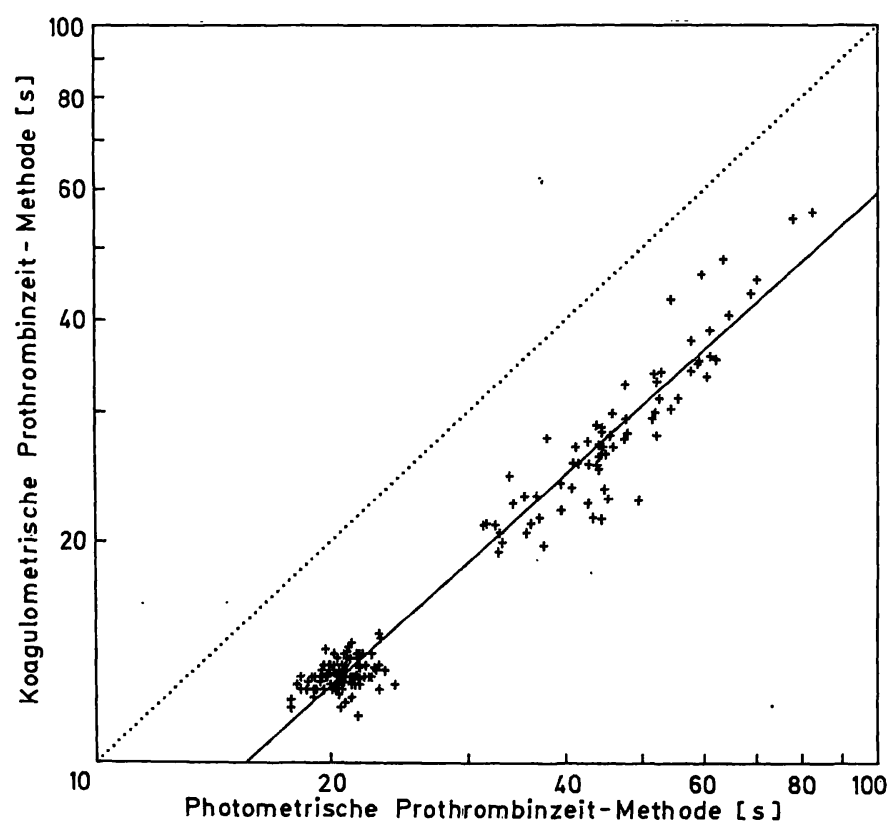

Abb. 9. Ermittlung des "International Sensitivity Index" für das chromogene Prothrombinzeit-Reagenz Charge 080284 (x) gegen den internen Standard Human-Placenta-Thromboplastin I (y) im Rahmen èiner externen Evaluierung.

Methode: Orthogonale Regression (29) (doppelt-logarithmische Skala):

$\log (y)=0,96 \log (x)-0,14 ; n=177 ;$ ISI: 1,09 
Vergleichsuntersuchungen mit konventionellen Prothrombinzeit-Methoden

Der Vergleich zwischen der photometrischen und zwei koagulometrischen Prothrombinzeit-Methoden wurde intern an kleineren Patientenkollektiven durchgeführt. In einer ersten Untersuchung wurde die photometrische Prothrombinzeit-Methode mit der Prothrombinzeit-Bestimmung mittels HumanHirn-Thromboplastin (British Comparative Thromboplastin Charge Nr. 099) unter Verwendung von 12 Plasmen mit normaler bzw. leicht verlängerter Prothrombinzeit und 17 Plasmen von oral Antikoagulierten verglichen.

In der zweiten Untersuchung wurden die Ergebnisse der photometrischen mit denjenigen der koagulometrischen Prothrombinzeit-Methode unter Verwendung eines standardisierten Human-Plazenta-Thromboplastins (Thromborel ${ }^{\circledR}$ S, Charge Nr. 080683) an 24 Plasmen von Patienten unter oraler Antikoagulation gegenübergestellt. Die statistische Auswertung erfolgte mit der Korrelationsmethode nach Passing \& Bablok, die keine Normalverteilung voraussetzt und keine Ausreißerelimination erfordert $(22,23)$.

Die Korrelationen des photometrischen und der koagulometrischen Tests erwiesen sich als sehr gut. Diese Korrelationen werden mit der Formel $\mathrm{y}=1,01 \mathrm{x}+$ 0,06 PR (chromogene Prothrombinzeit-Bestimmung versus koagulometrische Prothrombinzeit-Bestim- mung mit British Comparative Thromboplastin) (Abb. 10) bzw. $y=1,0 x+0,1$ PR (chromogene Prothrombinzeit-Bestimmung versus koagulometrische Prothrombinzeit-Bestimmung mit standardisiertem Human-Plazenta-Thromboplastin) (Abb. 11) charakterisiert. Die in einem externen Zentrum an 103 Patienten durchgeführte Überprüfung bestätigte die intern festgestellte gute Korrelation zwischen den verschiedenen Techniken: $y=0,97 x+0,05 P R$ (chromogene Prothrombinzeit-Bestimmung versus koagulometrische Prothrombinzeit-Bestimmung mit Human-Plazenta-Thromboplastin I).

\section{Patienten mit Lebererkrankungen}

Mit der photometrischen Prothrombinzeit-Methode wurden verschiedene Patientengruppen untersucht. Über die Erfahrungen mit der hier untersuchten Prothrombinzeit-Methode zur Kontrolle der oralen Antikoagulantientherapie wird in einer anderen Arbeit berichtet (31). Bei Leberpatienten, die in erster Linie eine Leberzirrhose aufwiesen, zeigten 5 von $12 \mathrm{Kran}$ ken Prozent-der-Norm-Werte unterhalb des Referenzbereichs. Die gleichen Patienten wurden auch mit zwei koagulometrischen Methoden untersucht. Abbildung 12 stellt die drei Methoden gegenüber. In den meisten Fällen geben alle ProthrombinzeitMethoden vergleichbare Resultate.

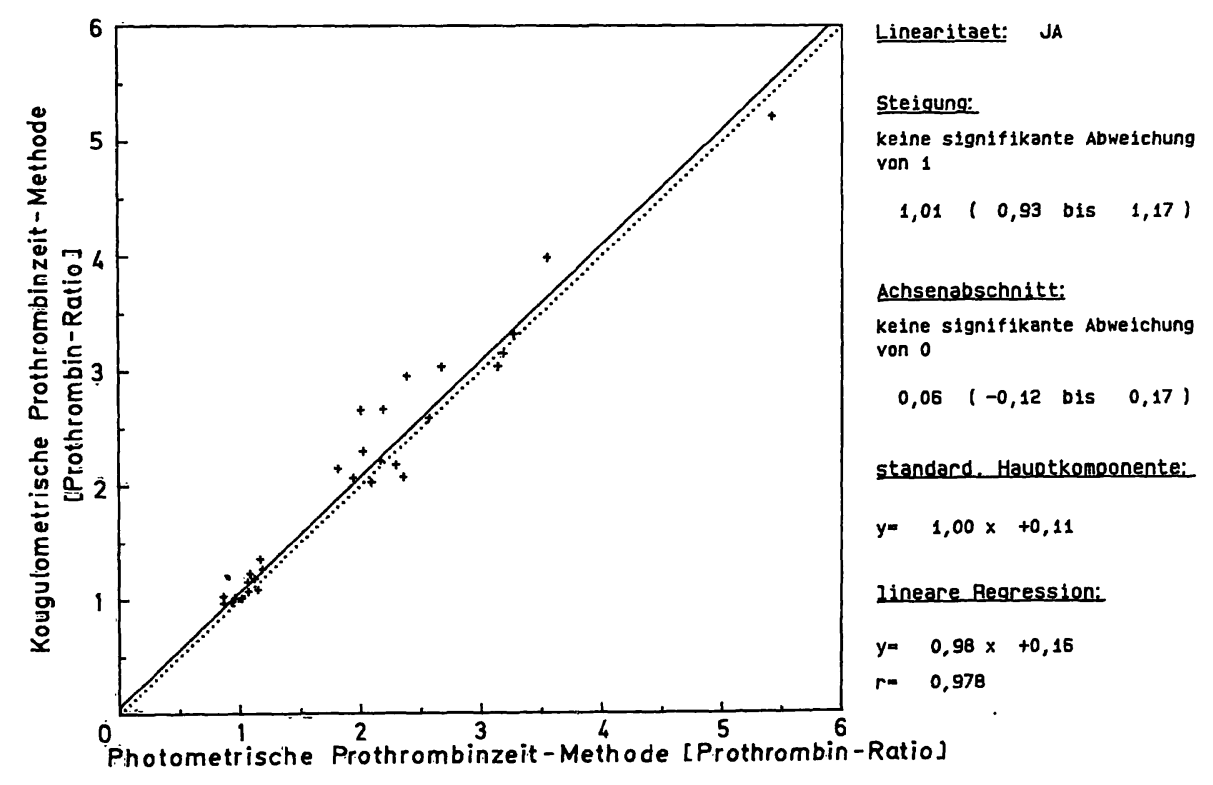

Abb. 10. Vergleich von Prothrombinzeit-Bestimmungen $n=29$ mittels der photometrischen Methode ( $x$ ) und eines koagulometrischen Tests mit dem British Comparative Thromboplastin (Charge Nr. 099) (y) auf der Basis von Prothrombin-RatioWerten.

Methode nach Passing \& Bablok (23):

$y=1,01 x+0,06$ 


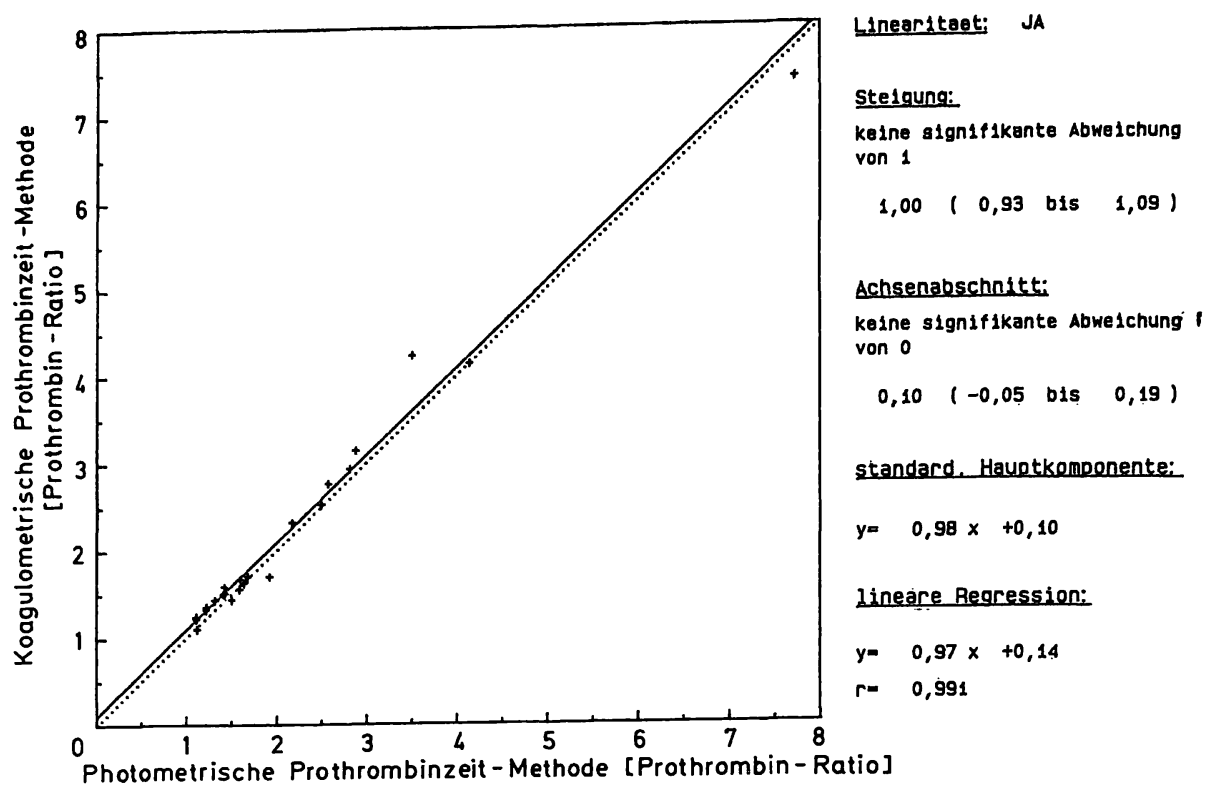

Abb. 11. Vergleich zwischen der photometrischen Prothrombinzeit-Methode $(x)$ und dem koagulometrischen ProthrombinzeitTest $(n=24)$ mit standardisiertem Human-Plazenta-Thromboplastin (Thromborel ${ }^{\circledR} S$ Charge Nr. 130683) (y). Methode nach Passing \& Bablok (23): $y=1,00 x+0,10$
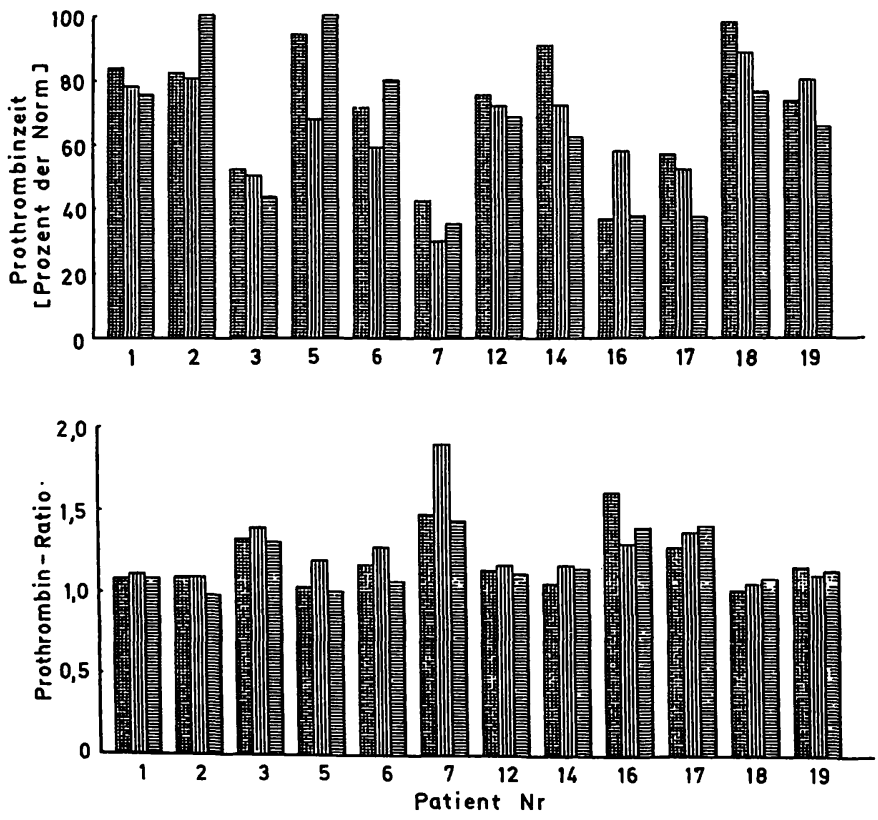

Abb. 12. Gegenüberstellung der Prothrombinzeit-Bestimmung mit der photometrischen Prothrombinzeit-Methode und mit koagulometrischen Tests unter Verwendung von zwei Human-Plazenta-Thromboplastinen in Plasmen von Patienten mit Leberzirrhose:

a) Werte in "Prothrombin-Ratio" und

b) Werte in "Prozent der Norm".

\section{Photometrische Prothrombinzeit-Methode}

Koagulometrische Prothombinzeit-Methode mit Human-Plazenta-Thromboplastin I

Koagulometrische Prothrombinzeit-Methode mit Human-Plazenta-Thromboplastin II

\section{Diskussion}

Durch die Bereitstellung von Referenzpräparationen für Thromboplastin, durch die von der WHO propagierte Standardisierung der verschiedenen Thromboplastine und mit dēr Einführung des „International Sensitivity Index“ bzw. der „International Normalized Ratio" sind erhebliche Fortschritte in der Standardisierung der Prothrombinzeit-Bestimmung erżielt worden $(3,27,28,30)$. Nicht standardisierbar war bis jetzt, bedingt durch die unterschiedlichen Verfahren, die Erfassung des Eintritts der Gerinnselbildung bei der Prothrombinzeitbestimmung. Insbesondere für die Kontrolle der oralen Antikoagulation zeigt sich hier der Nachteil unterschiedlicher Konzentrationen von Fibrinogen als natürlichem Substrat bei den konventionellen Methoden. Diese verwenden das im Patientenplasma enthaltene Fibrinogen zur Endpunktdetektion der Prothrombinzeit, obwohl gerade die Konżentration des Fibrinogens sehr stark variieren kann $(32,33)$. Der grundsätzliche Nachteil dieser Verfahren zur Bestimmung der Prothrombinzeit (und der partiellen Thromboplastinzeit) kann durch Einsatz eines Reagenzes für die Prothrombinzeit-Bestimmung beseitigt werden, bei dem der Endpunkt mit Hilfe eines synthetischen, für Thrombin spezifischen, chromogenen Substrats, das immer in gleicher Konzentration vorliegt, ermittelt wird. Bei dem hier beschriebenen neuen chromogenen Verfahren für die Prothrombinzeit-Bestimmung wird der Endpunkt durch die Photometrie, die wesentlich besser standardisierbar ist, bestimmt. Die Meßgröße beim photome- 
trischen Verfahren ist die Zeit, die bis zum Erreichen einer festgelegten Differenz der Absorbanz von 0,1 benötigt wird, $d$. h. es wird die Zeit erfaßt, in der im Plasma infolge der Aktivierung des exogenen Weges durch das im Reagenz enthaltene Human-PlazentaThromboplastin so viel Thrombin entstanden ist, daß eine konstante Menge an chromogenem Substrat umgesetzt wurde. In diese Zeitmessung geht der Fibrinogengehalt der Probe nicht ein; er kann aber über die Trübungszunahme geschätzt werden, da nach erfolgter Hydrolyse des chromogenen Substrates auch die Umwandlung des Fibrinogens in das Fibrin einsetzt. Dadurch wird verhindert, daß im präoperativen Screening Patienten mit normalem exogenen System, aber stark vermindertem Fibrinogengehalt übersehen werden.

Die Exaktheit einer photometrischen Messung spiegelt sich in der sehr guten Reproduzierbarkeit der neuen Prothrombinzeit-Methode wieder, die durch Intra-assay-Variationskoeffizienten von zum Teil unter $1 \%$ und Inter-assay-Variationskoeffizienten unter $2 \%$ (bezogen auf die Reaktionszeit in s) belegt wird. Die Spreizung der Bezugskurve führt auch bei Umrechnung der Meßzeit in „Prozent der Norm“ zu guten Variationskoeffizienten, die für eine „Gerinnungsmethode" mit 1 bis $3 \%$ in der Serie und mit 2 bis $6 \%$ von Tag zu Tag sicher als sehr gut bezeichnet werden können.

Die hohe Präzision der Methode erlaubt die Verwendung von chargenspezifischen Bezugskurven.

Neben einer guten Präzision $(19,34)$ ist wichtigstes Kriterium für die Brauchbarkeit eines Reagenzes für die Prothrombinzeit-Bestimmung seine Empfindlichkeit für einen Mangel der verschiedenen Faktoren des exogenen Gerinnungssystems, die Vitamin K-abhängig sind, wie F II, F VII und F X, und bei der oralen Therapie mit Vitamin K-Antagonisten stark variieren können. Die Ergebnisse der in=vitro Untersuchungen bezüglich Faktorenempfindlichkeit und der Untersuchungen an Patienten mit angeborenen Faktorenmängeln konnten zeigen, daß das neue chromogene Reagenz für die Prothrombinzeit-Bestimmung, auch bedingt durch das verwendete empfindliche Human-Plazenta-Thromboplastin, problemlos eine Verminderung der wichtigen Faktoren bereits ab Aktivitäten von 75 bis $50 \%$ anzeigt. Die hohe Empfindlichkeit gegenüber F VII erlaubt eine zuverlässige Überwachung der Patienten in der Einstellphase der oralen Antikoagulantientherapie. Auch die Übergangsphase von Heparin auf Cumarinderivate kann mit der photometrischen Prothrombinzeit-Methode exakt überwacht werden, da das Reagenz einen Neutralisationseffekt für Heparin bis auf Konzentrationen von 1 bis $1,25 \mathrm{IU} / \mathrm{ml}$ Plasma besitzt.
Die photometrische Prothrombinzeit-Bestimmung wird durch Hämoglobin (bis etwa $5-10 \mathrm{~g} / \mathrm{l}$ ), Bilirubin (bis mindestens $300 \mu \mathrm{mol} / \mathrm{l}$ ) und Triglyceride (bis mindestens $6 \mathrm{mmol} / \mathrm{l}$ ) nicht beeinflußt.

Auch erhöhte bzw. erniedrigte Fibrinogenkonzentrationen und erhöhte Fibrin(ogen)-Spaltprodukte haben wenig Einfluß auf die mittels chromogenen Substrates bestimmte Prothrombinzeit im Gegensatz zur koagulometrischen Prothrombinzeit-Methode. Der Einfluß von erhöhten Fibrinogenkonzentrationen wurde durch den Zusatz von humanem Fibrinogen zu verschiedenen Plasmaproben überprüft.

In keinem Fall konnte eine Störung der photometrischen Prothrombinzeit-Bestimmung durch andere plasmatische Proteasen wie Kallikrein, Plasmin, Urokinase, die eventuell das Reagenz in seinem Tripeptidbereich spalten könnten, festgestellt werden. Dies ist sicherlich auch auf die Gesamtstruktur einschließlich des Chromophors des Substrates zurückzuführen, das eine gute Spezifität für Thrombin aufweist (20).

Im Rahmen der Standardisierung des chromogenen Prothrombinzeit-Reagenz gegenüber internationalen Referenzpräparationen von Human-Hirn-Thromboplastin und internen Standards konnte eine gute Vergleichbarkeit sowohl mit dem British Comparative Thromboplastin als auch mit einem standardisierten Thromboplastin aus humaner Planzenta festgestellt werden. Die interne Standardisierung des chromogenen Reagenzes für die Prothrombinzeit-Bestimmung ergab einen "International Sensitivity Index“ von 1,03, der im Rahmen der externen Erprobung weitgehend bestätigt werden konnte.

Die für jede Charge des neuen chromogenen Prothrombinzeit-Reagenz durchgeführte Kalibrierung anhand der Richtlinien des Int. Committee for Standardization in Haematology (ICSH) und des Int. Committee on Thrombosis and Haemostasis (ICTH) (30) erlaubt die Angabe des „International Sensitivity Index" jeder Charge und den Ausdruck von Umrechnungstabellen. Diese Tabellen lassen die Beziehung zwischen konventionell ausgedrückten Resultaten des Prothrombinzeit-Tests in Prozent der Norm bzw. Prothrombin-Ratio und der International Normalized Ratio erkennen. Damit ist mit diesem Reagenz die Vereinheitlichung der Prothrombinzeit bei der Überwachung der oralen Antikoagulation möglich.

Diese Standardisierung zusammen mit der hohen Empfindlichkeit des chromogenen Reagenzes für die photometrische Prothrombinzeit-Bestimmung, die sich im Bereich zwischen 1,0 und 1,2 ISI bewegt, gewährleistet, daß bei der Verwendung der photome- 
trischen Prothrombinzeit-Methode als Kontrolltest eine zuverlässige orale Antikoagulantien-Therapie vorgenommen werden kann.

Die mit dem chromogenen Prothrombinzeit-Reagenz erzielten Werte entsprechen denen herkömmlicher koagulometrischer Prothrombinzeit-Tests, so daß die Angaben der Ergebnisse in „Prozent der Norm" und noch besser in "Prothrombin-Ratio" ohne weiteres vergleichbar sind. Sowohl bei Vergleichsuntersuchungen mit dem Standard „British Comparative Thromboplastin" als auch mit einem internen Thromboplastinstandard ergab sich eine gute Korrelation. Diese drückt sich in Korrelationskoeffizienten von 0,978 bzw. 0,991 bei der linearen Regressionsanalyse oder in Steigungen der Regressionsgeraden und in y-Achsenabschnitten, die sich nicht signifikant von 1 (bei der Steigung) und von 0 (beim y-Achsenabschnitt) unterscheiden, aus.

\section{Schlußfolgerungen}

Zusammenfassend kann festgestellt werden, daß die neue chromogene Prothrombinzeit-Methode als photometrisches Verfahren eine genaue Bestimmung der Prothrombinzeit erlaubt und eine gute Mechanisierbarkeit mit sich bringt. Die einfache Durchführung sollte eine Einführung dieser Methode im Routinelabor ermöglichen. Das chromogene Reagenz für die Prothrombinzeit-Bestimmung ist empfindlich, standardisiert und das Verfahren störungsfrei. Es ist gut geeignet sowohl für die Überwachung der oralen Antikoagulantien-Therapie als auch für das präoperative Screening.

\section{Danksagung}

Für die wertvolle Hịlfestellung bei der Entwicklung des Reagenzes, bei der Durchführung verschiedener Versuche, bei der statistischen Auswertung und bei der Diskussion der Ergebnisse und bei der Fertigstellung des Manuskriptes dieser Arbeit möchten sich die Autoren bei Frau Deubel, Herrn Debus und Herrn Buckler, bei Herrn Dr. Huber, bei Frau Langhoff und Herrn Gentzer, bei Herrn Dr. Becker und bei Frau Heberle besonders bedanken.

20. Kolde, H.-J., Eberle, R., Stüber, W. \& Heber, H. (1985) Thromb. Haemostas. 54, 148.

21. Poller, L. A. (1967) Lancet $I, 491$.

22. Lötz, A., Vogt, W., Popp, B. \& Knedel, M. (197.6) Comp. Biomed. Res. 9, $21-30$.

23. Passing, H. \& Bablok, W. (1983) J. Clin. Chem. Clin. Biochem. 21, 709-720.

24. Eisenwiener, H.-G., Bablok, W., Bardorff, W., Bender, R., Markowetz, D., Passing, H., Spaethe, R., Specht, W. \& Völkert, E. (1984) Lab. Med. 8, 232-244.

25. Kolde, H.-J. (1985) Behring Inst. Mitt. 78, 176-187.

26. Eisenwiener, H.-G., Bablok, W., Bardorff, W., Bender, R., Markowetz, D., Passing, H., Spaethe, R. \& Specht, W. (1983) Lab. Med. 7, 273-281.

27. WHO Expert Committee on Biological Standardization (1977) 28th Report. WHO Technical Report Series 610, pp. $14-15$ and pp. $45-51$.

28. Kirkwood, T. B. L. (1983) Thromb. Haemostas. 49, $238-$ 244.

29. Van der Velde, E. A. (1984) In: Thromboplastin Calibration and Oral Anticoagulant Control (van den Besselaar, A. M. H. P., Grabnick, H. R. \& Lewis, S. M., eds.) pp. 25-39, Martinus Nijhoff Publishers, Boston.

30. International Committee for Standardization in Haematology and International Committee on Thrombosis and Haemostasis (1985) Thromb. Haemostas. 53, 155-156.

31. Keller, F., Huber, J., Dati, F., Kolde, H.-J., Meyer, J. \& Kochsiek, K. (1986) Klin. Wochenschr., im Druck.

32. Trobisch, H. \& Adam, H.-G. (1984) In: Neue Aspekte in der Gerinnungsdiagnostik (Róka, L. \& Spanuth, E., Hrsg.) pp. $31-57$, Schattauer-Verlag, Stuttgart.

33. Tripodi, A. \& Mannucci, P. M. (1984) Clin. Chem. 30, $1392-1395$

34. Müller-Berghaus, G., Thiel, W. \& Watzka, B. (1985) Haemostasis $15,46-47$.

\author{
Dr. Francesco Dati \\ Behringwerke AG \\ Postfach 1140 \\ D-3550 Marburg
}

15. Paulssen, M. M. P., Kolhorn, A., Rothuizen, J. \& Planje,

M. C. (1979) Clin. Chim. Acta 92, 465-468.

Lab. Med. 9, 153.

17. Kolde, H.-J. \& Fuhge, P. (1984) Blut 49, 145-146.

18. Kolde, H.-J. \& Dati, F. (1985) Haemostasis $15,71$.

19. Dati, F. \& Kolde, H.-J. (1985) J. Clin. Chem. Clin. Biochem. $23,577-578$. 